\title{
Correlates of ART Adherence among Pregnant and Breastfeeding Mothers Initiated on Life Long ART for People Living with HIV/AIDS (LLAPLA) in One Public Health Unit in the Hhohho Region
}

\section{Maseko TSB $^{1 *}$ and Masuku SKS}

1International Centres for AIDS Care and Treatment Programmes, Research Unit, Swaziland

${ }^{2}$ University of Swaziland, Department of Community Health Nursing Science, Swaziland

\begin{abstract}
Background: The prevalence of HIV among pregnant women and the risk vertical transmission of HIV necessitate attention. In the absence of appropriate interventions, about a third of children born to HIV-positive women are likely to be infected. Almost all children infected with HIV are infected through vertical or mother-to-child transmission. The introduction of life lifelong ART for people living with HIV (LLAPLA) among pregnant is a necessary intervention in the prevention of mother to child transmission. In order for LLAPLA to be effective and efficient, it requires full cooperation of clients by good adherence. Lack of commitment by clients will render the programme ineffective. Hence it is important to understand the factors that influence adherence to LLAPLA. The purpose of the study was to describe the correlates of LLAPLA among pregnant and breastfeeding women on ART.
\end{abstract}

Methods: A cross-sectional survey was conducted among pregnant and breastfeeding women on ART at Mbabane PHU. Data was collected through face to face interviews using a structured questionnaire. Univariate, bivariate and multivariate analysis was done.

Results: About $65 \%(n=158)$ participants had good adherence to ART while $31 \%(n=76)$ had poor adherence. Factors significantly associated to adherence were participant's level of education $(p=0.009)$, having a problem of forgetfulness $(p=0.021)$, being listened to by the health worker $(p=0.008)$ and having nice communication with the health worker $(p=0.008)$. Predictors of good adherence were not having a problem of forgetfulness $(p=0.015)$, the woman financially depending on her relatives $(p=0.021)$ or being self-sustained financially $(p=0.013)$ and not hiding ARVs from partner $(p=0.004)$. There is still a need for more studies at a national level to investigate measures to improving adherence to LLAPLA.

Keywords: Prevention of mother to child transmission; LLAPLA; ART adherence; Mother to child transmission of HIV

\section{Background}

For the past three decades, human immunodeficiency virus (HIV) infection has remained a major global public health concern. Morbidity and mortality rates have continued to negatively impact the life expectancy of many developing and underdeveloped nations. On estimation, about 35 million people live with HIV globally. Of the global HIV prevalence rate, about $67 \%$ comes from sub-Sahara African region, and this region accounts for $72 \%$ of the world's HIV related mortalities [1]. Current estimates suggest that between 21.4 and 25.7 million adults live with HIV/AIDS in Sub-Saharan Africa. Well over half of these are believed to be women. In the absence of appropriate interventions, about a third of children born to HIV-positive women are likely to be infected. Presently, around 2000000 children are estimated to live with HIV in Sub-Saharan Africa. Close to 700000 infants and children were infected in 2003 alone, and almost all of these were infected through vertical or mother-to-child transmission (MTCT). Vertical transmission refers to the transmission of HIV from HIV infected mothers to their babies, during pregnancy, labour, delivery and breastfeeding [2].

\section{HIV/AIDS in Swaziland}

In Swaziland, one of the sub-Saharan African countries hard hit by HIV, from the first HIV reported case in 1986, HIV has been rampantly spreading throughout the population [3]. The current prevalence rate is $26 \%$ in the reproductive age group of $15-49$ years [4]. HIV has had various negative effects in Swaziland. Mortality from HIV/AIDS lowered life expectancy in Swaziland by 17 years, in the period 1997 to 2003 [5] and currently stands at 48 years, enlisting it among the lowest in the world [6]. This loss of life expectancy prevents individuals from contributing fully to the economic development, and has long lasting implications for social fabric and structure of families. Reduced life expectancy affects the survival of whole communities, the social capital within them, and erodes the saving capacity of both households and firms [5]. This has overwhelmed the capacity of the extended family to cope, resulting in an increased number of child headed households, poverty and destitution. The crude death rate has more than doubled from 13.1 deaths per 1000 population in 1997 to 31.1 deaths per 1000 population in 2007. Annual AIDS deaths were projected to increase from 7,114 in 2009 to 8,389 by 2015 [7].

HIV has also taken its tall among childbearing women, leading MTCT. For instance, in Swaziland, among pregnant women receiving antenatal care (ANC), HIV infection has been steadily increasing from

*Corresponding author: Thokozani SB Maseko, Research Project Coordinator University Research Co., LLC, Research Unit, Sozisa Rd, Mbabane Office Park, North Wing, 3rd Floor, Mbabane, Hhohho H100, Swaziland, Tel: +26876254021; +26876254021; E-mail: tsb139099@gmail.com

Received March 14, 2017; Accepted March 23, 2017; Published March 30, 2017

Citation: Maseko TSB, Masuku SKS (2017) Correlates of ART Adherence among Pregnant and Breastfeeding Mothers Initiated on Life Long ART for People Living with HIVIAIDS (LLAPLA) in One Public Health Unit in the Hhohho Region. J AIDS Clin Res 8: 681. doi: 10.4172/2155-6113.1000681

Copyright: (C) 2017 Maseko TSB, et al. This is an open-access article distributed under the terms of the Creative Commons Attribution License, which permits unrestricted use, distribution, and reproduction in any medium, provided the original author and source are credited. 
Citation: Maseko TSB, Masuku SKS (2017) Correlates of ART Adherence among Pregnant and Breastfeeding Mothers Initiated on Life Long ART for People Living with HIVIAIDS (LLAPLA) in One Public Health Unit in the Hhohho Region. J AIDS Clin Res 8: 681. doi: 10.4172/21556113.1000681

Page 2 of 8

$3.9 \%$ in 1992 to $41.1 \%$ in 2010 [8] as shown in Table 1. It has contributed to the increase in orphaned and vulnerable children. Orphaned and vulnerable children were 104,026 in 2010 [6], which are $15 \%$ of the population in Swaziland [7]. Hence there is a need to prevent vertical transmission of HIV cannot be overemphasised.

The increase of HIV infection in children is reversing gains made in child mortality, and is lowering life expectancies significantly in the worst-hit countries, such as Swaziland. About half of the children who are infected with HIV through vertical transmission develop AIDS symptoms and die within the first two (2) years of life [2]. The child infected through MTCT is also at risk of being orphaned, as the mother, and probably the father too would be infected with HIV too. In the absence of efficient life-prolonging interventions, the likelihood of parent(s) dying within 8-10 years after acquiring HIV infection is high. Recent estimates suggest that there are nearly 14 million orphans in Africa, and this number was projected to rise to a staggering 25 million by the year 2010 [6].

\section{Response to MTCT of HIV}

In an effort to reduce MTCT, a programme called Prevention of Mother to Child Transmission of HIV (PMTCT) was initiated in many countries. For instance, in Swaziland, PMTCT programme was launched in 2003 by the Ministry of Health and Social Welfare and had expanded to 137 facilities by the year 2009 [9]. In Swaziland, a four pronged approach to the prevention of HIV infection in women and infants has been adopted including primary prevention of HIV. These prongs are: prevention of unintended pregnancies among HIV positive women; reduction of mother-to-child-transmission of HIV among HIV positive women, and the provision of treatment, care and support for HIV positive women, and providing care and support to their families. In addition, care of HIV-exposed infants and diagnosis of HIV infection in infants are part of PMTCT services [3].

Initially, PMTCT programme required mothers to be tested for HIV as soon as they book for ANC to determine their HIV status. Those women found to be HIV positive were counselled, given support and started on preventive therapy (monotherapy) during pregnancy. They were then given an intra-partum dose during labour to suppress HIV replication hence prevent the transmission of HIV to their unborn babies during pregnancy and labour [10]. Upon giving birth the women were expected to choose a suitable feeding method that would ensure mother-to-child-transmission of HIV is reduced, yet should be affordable to the mother. The infant feeding methods include exclusive breastfeeding for the first six (6) months and then supplementary feeding from 6 months onwards or the mother can opt for exclusive replacement feeding. The baby was also given nevirapine during the period of breastfeeding [11].

Recently, modification to PMTCT has been made. Mothers are now tested for HIV at the facility at their first ANC booking as it was done before. If the mother is found to be living with HIV, she is initiated on antiretroviral therapy (ART) as a lifelong therapy. This programme called Life Long ART for People Living with HIV/AIDS (LLAPLA). In this programme, mothers living with HIV are no longer given a monotherapy (one ARV drug) but are started on standard care for people living with HIV and ART. The baby is no longer given any ARVs at birth if the mother chooses to breastfeed (exclusive breastfeeding). This is based on the understanding that the baby gets the drugs from the mother's milk, and giving the baby ART would lead to drug overdose to the baby [11].

In order for LLAPLA to be effective and efficient, it requires full cooperation of the mothers in terms of good adherence. Lack of commitment by mothers makes the programme ineffective. Strategies that have been put in place to promote adherence include educating mothers on the importance of PMTCT, pill counting by health care providers each time women come for refill and making follow-up for those who are lost to care [12]. In the absence of interventions to prevent mother-to-child-transmission of HIV, about $15-25 \%$ of infants of HIV infected women will be infected during pregnancy or delivery, and an additional 5-20\% may become infected during breastfeeding [2]

\section{Adherence to LLAPLA}

Life Long ART for People Living with HIV/AIDS (LLAPLA) is relatively a new initiative in PMTCT. LLAPLA has a great potential of reducing mother-to-child transmission of HIV if well followed. Success of this program lies on understanding of individual characteristic, health facility related factors and family/society related factors that influence adherence of patients to ART (LLAPLA). Adherence to treatment varies among patients. Adherence to ART is generally influenced by many factors such as demographic, economic, sociocultural and individual factors such as acceptance of one's HIV status [2].

In other studies, a depressed mood and having mental health problems are consistent predictors of poor adherence. Patients end up defaulting treatment either due to that they were not thinking straight or due to that they had prolonged depression which results in forgetfulness [12]. Some women end up taking their medication incorrectly either because of difficulty in understanding the English drug instructions or because of alternative health beliefs or some people just do not care about themselves or they may lack the competency to self-care [10].

Adherence is also influenced by the interaction between the patient and the provider. In order to achieve engagement with the patient, the health care provider needs to use a range of inter-personal and clinical skills. These include listening, being sensitive to the needs and limitations of the patient, developing understanding of the patient's situation, having good communication skills, particularly the ability to translate complex information into a format that is both detailed and understandable to the patient. It also includes the ability to recognize the patient as a partner in his/her own health decisions [12]. Patients who perceive that the health care provider-patient relationship is one of mutual respect and trust are more likely to be adherent; and they are able to open-up and be honest about problems associated with adherence to ART. Emphasis on medication adherence must also be prioritized with each visit to the healthcare facility [7]. It must not be assumed that a patient was taught at some point in the care continuum. Information may fade away if it is not repeated to the patient.

Adherence may also be affected by social related factors such as stigmas, fear of abuse and youth unfriendly services. Some women are unable to disclose their status within their families and to their in-laws

\begin{tabular}{|c|c|c|c|c|c|c|c|c|c|c|}
\hline Year & 1992 & 1994 & 1996 & 1998 & 2000 & 2002 & 2004 & 2006 & 2008 & 2010 \\
\hline Prevalence (\%) & 3.9 & 16.1 & 26.0 & 31.6 & 34.2 & 38.6 & 42.6 & 34.2 & 42.0 & 41.1 \\
\hline
\end{tabular}

Table 1: Mapping of HIV prevalence among pregnant mothers in 1992-2010. 
Citation: Maseko TSB, Masuku SKS (2017) Correlates of ART Adherence among Pregnant and Breastfeeding Mothers Initiated on Life Long ART for People Living with HIVIAIDS (LLAPLA) in One Public Health Unit in the Hhohho Region. J AIDS Clin Res 8: 681. doi: 10.4172/21556113.1000681

Page 3 of 8

for fear of rejection and stigmatization. These women often default treatment. Some women end up hiding their anti-retroviral medication from their partners due to non-disclosure secondary to fear of being ostracized, resulting to poor adherence to treatment and failure to honour clinic visit schedules [13]. Therefore, as long as issues of stigma towards HIV are not dealt with intensely, people will have difficulty with ART adherence. On another note, being in a stable relationships and having access to social and emotional support are also important factors in maintaining adherence. People who live alone and have poor social networks are more likely to have problems with adherence than those who do not. Hence fear of stigma and being noticed when taking ART by those outside one's immediate social network presents a barrier to normalizing adherence behaviour to ART [12].

Secondary to severe side effects of anti-retroviral drugs (ARVs), some patients fail to tolerate ARVs. Anti-retroviral drugs (ARVs) are better tolerated by adequately nourished patients, and like any other medication, ARVs need to be taken with food [9]. While ART should not be delayed for patients in deteriorating health, the regime is harder for those with food security issues. Food and nutrition interventions (such as therapeutic feedings) may improve ART effectiveness and adherence. Hence the availability of food can be one factor affecting patients' adherence to LLAPLA among pregnant women.

The issue of adherence to LLAPLA needs to be intensified to effectively achieve PMTCT. LLAPLA is a relatively new initiative, and one to continue in use, therefore it is important to understand the adherence level of mothers initiated on LLAPLA, and the factors that influence their adherence. Adherence has three categories, namely, poor adherence $(<95 \%)$, good $(95-100 \%)$ or there can be over adherence whereby patients appear to exceed good adherence levels (>105\%). Poor and over adherence is signs of not taking medication properly [11]. About $23 \%$ of women initiated on LLAPLA defaulted treatment during pregnancy or soon after delivery at Mbabane Public Health Unit (PHU) [14], yet factors affecting adherence to LLAPLA among mothers attending care at Mbabane PHU are poorly understood, hence the need for this study. The purpose of the study was to assess the extent to which mothers living with HIV adhere to LLAPLA. It also assessed the factors that influence the mother's adherence to LLAPA and statistically determined the factors that significantly influenced these mothers' adherence to LLAPLA.

\section{Methodology}

Using a quantitative approach, a cross-sectional survey was conducted at Mbabane Public Health Unit (PHU). The study population was a total of 461 pregnant and lactating women who attended ART services at Mbabane PHU [15]. For a population of 461 , at $95 \%$ confidence level and allowing an error factor of 5\%, a sample size of 210 participants was required to observe a response distribution of $50 \%$ (www.raosoftsamplesize.html). A total of 245 randomly selected participants were recruited into the study. Face to face interviews were conducted using a structured questionnaire which was in the participant's preferred language (SiSwati or English). The questionnaire had five sections: socio-demographic data, economic status, intra-personal factors, socio-cultural factors and health facility related factors, and all responses were predetermined. Questions were read to the participants and their response was chosen from the provided responses. Information on ART adherence was extracted from the participant's ART card which is calculated at every ARVs refill visit. Pretesting of questionnaire was done at Zulwini Clinic, a baby clinic to Mbabane PHU, that is, they have the same health provision practices of LLAPLA and hence it was a good site for pretesting. Before data collection, ethical clearance was obtained from the Swaziland Scientific and Ethics Committee, (ethical approval number, MH/599C/ FWA00015267/IRB0009688) and permission to conduct the study was sought at Mbabane PHU. A signed informed was obtained from each participant and data collection was done in a private room within the health facility.

\section{Data Analysis}

Analysis was done using SPSS Version 20 (IBM Corp., Armonk, NY, USA). The first step of analysis was to describe the level of adherence and the assessed factors using descriptive statistics and summarized in Tables 2-5. To measure associations, bivariate One-way ANOVA and Independent $\mathrm{t}$ - test were used to investigate the association between assessed factors and level of ART adherence. To determine the direction of the associations Pearson's correlation ( $r$ ) was done for all significant associations and regression analysis was done to identify factors that predicted adherence. Statistical significance was set at $\mathrm{p}<0.05$

\section{Results}

A majority ( $33 \%, \mathrm{n}=82)$ of the participants were in the ages $22-26$ years while $24 \%(n=60)$ were in the ages $17-21$ years. The mean age was $27.4 \pm 7.7$ years with a minimum age of 17 years, a maximum of 51 years and a range of 34 . All (100\%) participants were Swazis and $56 \%(n=136)$ did not stay with their partners. About 65\% $(n=158)$ participants had good adherence to ART while $31 \%(n=76)$ had poor adherence. A majority $(69 \%, \mathrm{n}=169)$ of the participants had secondary/ high school education while only $7 \%(\mathrm{n}=17)$ had tertiary education. Most $(58 \%, n=142)$ participants were single, while $22 \%(n=54)$ were married. Data is show in Table 1.

\section{Socio-Economic Factors}

A majority $(33 \%, n=82)$ of the participants were employed while $29 \%(n=71)$ were housewives and another $29 \%(n=71)$ did some outside work. More than half $(67 \%, n=164)$ had a monthly family income less than E2000. Only $33 \%(n=82)$ of the participants reported that they had financial-transport problems to the health facility and $27 \%(n=66)$ sometimes had no food in the house. A majority $(60 \%, n=147)$ of the participant's partners had secondary/high school education. More than half $(55 \%, n=135)$ participants were self-sustained financially while $38 \%(n=93)$ depended on their partner for financial support. Data is shown in Table 2 .

\section{Intra-Personal Factors}

Variation in the participants' intrapersonal factors was observed. About 64\% $(n=157)$ of the participants understood the English instructions written on their medications and about $84 \%(n=206)$ knew how to use their medications properly. While $69 \%(n=169)$ of the participants had a problem of forgetfulness, $16 \%(n=39)$ reported that they had a diagnosed mental health problem, and about $24 \%$ $(n=60)$ sometimes felt down and depressed. Even though 9\% $(n=22)$ of the participants had a child living with HIV, 91\% ( $n=223)$ had HIV negative children due to PMTCT program. Data is shown in Table 3.

\section{Patient-provider relationship factors}

When asked about their relationships with health workers, various responses were elicited from the participants. Most $(93 \%, n=228)$ participants felt that they were listened to by health works, and $91 \%$ $(n=221)$ felt that health workers were sensitive to their needs. Even though most $(98 \%, \mathrm{n}=240)$ participants felt that health workers understood their circumstances, $20 \%(n=49)$ felt that they were not 
Citation: Maseko TSB, Masuku SKS (2017) Correlates of ART Adherence among Pregnant and Breastfeeding Mothers Initiated on Life Long ART for People Living with HIVIAIDS (LLAPLA) in One Public Health Unit in the Hhohho Region. J AIDS Clin Res 8: 681. doi: 10.4172/21556113.1000681

Page 4 of 8

\begin{tabular}{|c|c|c|}
\hline Socio-demographic profile & $\mathbf{n}$ & $\%$ \\
\hline \multicolumn{3}{|l|}{ Age } \\
\hline $17-21$ & 60 & 24 \\
\hline $22-26$ & 82 & 33 \\
\hline $27-32$ & 44 & 18 \\
\hline $33-37$ & 32 & 13 \\
\hline $38-42$ & 26 & 11 \\
\hline $43-47$ & 0 & 0 \\
\hline $48-52$ & 3 & 1 \\
\hline \multicolumn{3}{|l|}{ Stay with partner } \\
\hline Yes & 109 & 44 \\
\hline No & 136 & 56 \\
\hline \multicolumn{3}{|l|}{ Ethnicity } \\
\hline Swazi & 245 & 100 \\
\hline \multicolumn{3}{|l|}{ Adherence to ART } \\
\hline Poor adherence & 87 & 35 \\
\hline Good Adherence & 158 & 65 \\
\hline \multicolumn{3}{|l|}{ Educational Level } \\
\hline Illiterate & 5 & 2 \\
\hline Primary & 54 & 22 \\
\hline Secondary/high school & 169 & 69 \\
\hline Tertiary & 17 & 7 \\
\hline \multicolumn{3}{|l|}{ Marital Status } \\
\hline Single & 142 & 58 \\
\hline Married & 54 & 22 \\
\hline Cohabiting & 44 & 18 \\
\hline Separated/divorced/widowed & 5 & 2 \\
\hline
\end{tabular}

Table 2: Socio-demographic profile of participants $(n=245)$.

\begin{tabular}{|c|c|c|c|c|}
\hline \multirow[t]{2}{*}{ Statement } & \multicolumn{2}{|l|}{ Yes } & \multicolumn{2}{|l|}{ No } \\
\hline & $\mathbf{n}$ & $\%$ & $\mathbf{n}$ & $\%$ \\
\hline Difficulty understanding English medication instructions & 88 & 36 & 157 & 64 \\
\hline Know how to take medications properly & 206 & 84 & 39 & 16 \\
\hline Have a problem of forgetfulness & 76 & 31 & 169 & 69 \\
\hline Have a diagnosed mental problem & 39 & 16 & 206 & 84 \\
\hline Feel down and depressed often times & 60 & 24 & 40 & 76 \\
\hline Have experienced serve side effects of ART & 39 & 16 & 206 & 84 \\
\hline \multirow[t]{2}{*}{ Have a child living with HIV } & 22 & 9 & 223 & 91 \\
\hline & & & $\mathbf{n}$ & $\%$ \\
\hline \multicolumn{5}{|l|}{ PMTCT helped me have a negative child before } \\
\hline \multicolumn{3}{|l|}{ N/A (first pregnancy) } & 86 & 35 \\
\hline \multicolumn{3}{|l|}{ Yes } & 137 & 56 \\
\hline \multicolumn{3}{|l|}{ No } & 22 & 9 \\
\hline \multicolumn{5}{|l|}{ Total number of pregnancies } \\
\hline \multicolumn{3}{|l|}{1} & 86 & 35 \\
\hline \multicolumn{3}{|l|}{2} & 76 & 31 \\
\hline \multicolumn{3}{|l|}{3} & 44 & 18 \\
\hline \multicolumn{3}{|l|}{4} & 27 & 11 \\
\hline \multicolumn{3}{|l|}{5} & 5 & 2 \\
\hline \multicolumn{3}{|l|}{6} & 5 & 2 \\
\hline \multicolumn{5}{|l|}{ Number of pregnancies prior to knowing HIV+ status } \\
\hline \multicolumn{3}{|l|}{1} & 88 & 36 \\
\hline \multicolumn{3}{|l|}{2} & 77 & 31 \\
\hline \multicolumn{3}{|l|}{3} & 71 & 29 \\
\hline \multicolumn{3}{|l|}{4} & 5 & 2 \\
\hline \multicolumn{3}{|l|}{5} & 5 & 2 \\
\hline
\end{tabular}

Table 4: Intra-personal factors of participants associated to adherence to ART $(n=245)$.

\begin{tabular}{|c|c|c|}
\hline & $\mathbf{n}$ & $\%$ \\
\hline \multicolumn{3}{|l|}{ Occupational status } \\
\hline Housewife & 71 & 29 \\
\hline Any outside work & 71 & 29 \\
\hline Employed & 82 & 33 \\
\hline Self-employed & 21 & 9 \\
\hline \multicolumn{3}{|l|}{ Family monthly income } \\
\hline$<2000$ & 164 & 67 \\
\hline 2000-3999 & 39 & 16 \\
\hline $4000-5999$ & 32 & 13 \\
\hline $6000-7999$ & 5 & 2 \\
\hline 8000-9999 & 5 & 2 \\
\hline \multicolumn{3}{|l|}{$\geq 10000$} \\
\hline \multicolumn{3}{|c|}{ Have financial transport problems } \\
\hline Yes & 82 & 33 \\
\hline No & 159 & 65 \\
\hline \multicolumn{3}{|c|}{ Always have food in the house } \\
\hline Yes & 179 & 73 \\
\hline No & 66 & 27 \\
\hline \multicolumn{3}{|c|}{ Partner's educational status } \\
\hline Illiterate & 17 & 7 \\
\hline Primary & 42 & 17 \\
\hline Secondary/high school & 147 & 60 \\
\hline Tertiary & 39 & 16 \\
\hline \multicolumn{3}{|l|}{ Financial status } \\
\hline Self-sustained & 135 & 55 \\
\hline Dependent of partner & 93 & 38 \\
\hline Dependent on relatives & 17 & 7 \\
\hline
\end{tabular}

Table 3: Socio-economic status of participants $(n=245)$.

considered in decision making. While most $(93 \%, \mathrm{n}=228)$ participants communicated nicely with health workers and understood the information provided $(91 \%, \mathrm{n}=223)$, some $(7 \%, \mathrm{n}=17)$ participants complained about rough treatment and $11 \%(\mathrm{n}=27)$ about poor counselling and support from health workers. Data is shown in Table 6.

\section{Socio-cultural factors}

Both negative and positive responses were observed from participants when asked about socio-cultural influences to their use of ART. Even though $80 \%(n=196)$ had disclosed their HIV status to someone, about $20 \%(n=49)$ had not, and $27 \%(n=66)$ had not disclosed to their partners. Fear of rejection by in-laws $(24 \%, n=60)$ and by partner $(16 \%, \mathrm{n}=86)$ were the reasons for non-disclosure. A majority $(80 \%, n=196)$ were in a stable relationship, and $91 \%(n=223)$ had good social support while $80 \%(\mathrm{n}=196)$ had good emotional support. A majority $(73 \%, n=179)$ of the participants still feared being stigmatised by society. Data is shown in Table 7 .

\section{Correlation Analysis of Factors Significantly Associated Adherence to ART}

To determine the relationship of the significantly associated factors to adherence as either positive or negative, correlation analysis was done. Various factors were significantly correlated to ART adherence. Having good emotional support positively correlated $(\mathrm{r}=0.375$, $\mathrm{p}=0.011)$ to ART adherence. Negative correlates of ART adherence were using alternative medicine $(\mathrm{r}=-0.312, \mathrm{p}=0.037)$, and having a problem of forgetfulness $(\mathrm{r}=-0.474, \mathrm{p}=0.001)$. 
Citation: Maseko TSB, Masuku SKS (2017) Correlates of ART Adherence among Pregnant and Breastfeeding Mothers Initiated on Life Long ART for People Living with HIVIAIDS (LLAPLA) in One Public Health Unit in the Hhohho Region. J AIDS Clin Res 8: 681. doi: 10.4172/21556113.1000681

Page 5 of 8

\begin{tabular}{|c|c|c|c|c|}
\hline \multirow[t]{2}{*}{ Statement } & \multicolumn{2}{|c|}{ Yes } & \multicolumn{2}{|c|}{ No } \\
\hline & $\mathbf{n}$ & $\%$ & $\mathbf{n}$ & $\%$ \\
\hline Health care workers do listen to me & 228 & 93 & 17 & 7 \\
\hline Health workers are sensitive to my needs and limitations & 223 & 91 & 22 & 9 \\
\hline Health workers try to understand my circumstances & 240 & 98 & 5 & 2 \\
\hline I'm considered as a partner in decision making & 196 & 80 & 49 & 20 \\
\hline Health workers remind me about medication adherence at every visit & 213 & 87 & 82 & 13 \\
\hline We communicate effectively with health workers & 228 & 93 & 17 & 7 \\
\hline Information they provide is understandable & 223 & 91 & 22 & 9 \\
\hline Health care workers are rough when treating me & 17 & 7 & 228 & 93 \\
\hline I receive poor counselling and support from health care workers & 27 & 11 & 218 & 89 \\
\hline We have a good patient provider relationship & 213 & 87 & 82 & 13 \\
\hline
\end{tabular}

Table 5: Patient-provider relationship factors associated to ART adherence of participants $(n=245)$

\begin{tabular}{|c|c|c|c|c|}
\hline \multirow[t]{2}{*}{ Statement } & \multicolumn{2}{|c|}{ Yes } & \multicolumn{2}{|c|}{ No } \\
\hline & $\mathbf{n}$ & $\%$ & $\mathbf{n}$ & $\%$ \\
\hline I have disclosed my HIV status to someone & 196 & 80 & 49 & 20 \\
\hline I have disclosed my HIV status to my partner & 179 & 73 & 66 & 27 \\
\hline I did not disclose my HIV status because afraid of rejection from my in-laws & 60 & 24 & 185 & 76 \\
\hline Hide medications from partner because of fear of rejection from partner & 39 & 16 & 206 & 84 \\
\hline I also use alternative medicine & 44 & 18 & 201 & 82 \\
\hline I'm in a stable relationship & 196 & 80 & 49 & 20 \\
\hline I have a good social support & 223 & 91 & 22 & 9 \\
\hline I have good emotional support & 196 & 80 & 49 & 20 \\
\hline Hospital service unfriendly & 44 & 18 & 201 & 82 \\
\hline Afraid of being stigmatised by society & 179 & 73 & 66 & 27 \\
\hline
\end{tabular}

Table 6: Shows socio-cultural factors related to adherence to ART by participants $(n=245)$.

Other observed significant positive correlations were being listened to by the health care worker and disclosing one's status to someone $(\mathrm{r}=0.535, \mathrm{p}=0.000)$, communicating effectively with the health care worker and having good emotional support $(\mathrm{r}=0.312, \mathrm{p}=0.037)$, being in a stable relationship and good emotional support $(\mathrm{r}=0.444, \mathrm{p}=0.002)$, being in a stable relationship and disclosing status to someone $(r=0.444$, $\mathrm{p}=0.002)$, having good social support and disclosing status to someone $(\mathrm{r}=0.625, \mathrm{p}=0.000)$ and having good emotional support and disclosing one's status to someone $(\mathrm{r}=0.306, \mathrm{p}=0.041)$.

Some significant negative correlations were between the factors. These were educational level and forgetfulness $(r=-0.347, p=0.020)$, nice communication with health care workers and using alternative medicine $(\mathrm{r}=-0.342, \mathrm{p}=0.022)$, good social support and forgetfulness $(\mathrm{r}=-0.465, \mathrm{p}=0.001)$, good emotional support and forgetfulness $(\mathrm{r}=-0.384, \mathrm{p}=0.009)$, and having good emotional support and using alternative medicine $(r=-0.349, \mathrm{p}=0.019)$. Data is show in Table 7 .

\section{Predictors of Adherence to LLAPLA}

Predictors to adherence to LLAPLA were observed using multiple linear regression analysis through forced entry method. The observed factors account for $68.3 \%(\mathrm{R}=0.683)$ of the observed adherence in the regression model with a significant model fit at $\mathrm{P}=0.000$. Predictors of good adherence were not having a problem of forgetfulness $(p=0.015)$, the woman financially depending on her relatives $(p=0.021)$ or being self-sustained financially $(\mathrm{p}=0.013)$ and not hiding ARVs from partner $(\mathrm{p}=0.004)$, as shown on Tables 8 and 9 .

\section{Discussion}

The study findings showed that a majority of the participants were adolescents, that is, $33.3 \%$ of the participants were in the ages $22-26$ years while $24.4 \%$ were in the ages $17-21$ years. Pregnancy in these ages is defined as teenage pregnancy, that is, pregnancy occurring in the ages 13-19 years [16]. The World Health Organisation extends it definition of adolescent pregnancy to cover late adolescent pregnancy, defined as ages of 21-24 years. Findings of this study on adolescent pregnancy concur with the observation that the proportion of births that take place during adolescence is more than $50 \%$ in sub-Saharan Africa [17]. Noting that a majority $(69 \%)$ of the participants had secondary/high school education, and only $7 \%$ had tertiary education concurs with the observation that adolescent pregnancy leads to drop out of school, and those women have none or low qualifications. A majority of the participants did not stay with their partners and were single. Adolescent pregnancy often leads to non-marriage and children born by those women grow up without a father [16]. Therefore, the adolescent pregnancy observed in this study is a cause for concern. Even though there was no significant association between the age and adherence to ART in this study, other studies have observed that being younger in age was a predictor of non-adherence $(p<0.001)$ among people living with HIV [18].

\section{Assessed Factors of Adherence to ART}

Only $33.3 \%$ of the participants were employed while $29 \%$ were housewives and a majority had a family income less than SZL2000. In Swaziland, the minimum wages for various workers are as follows: 531.6 Swazi emalangeni (\$76.50) per month for a domestic worker; 420 emalangeni $(\$ 60.50)$ a month for an unskilled worker 600 emalangeni (\$86.50) a month for a skilled worker [19]. This low rate of employment and dependency to their partners relates to the participants' low educational status. Women with low education are likely to be unemployed or low-paid and as such live in poverty, that is, sometimes have no food in this house and have financial related transport problems to that health facility [17] as observed in the study. Even though employment status or level of income were not significantly associated with ART adherence in this study, these factors have been significant in other studies. For instance, in 
Citation: Maseko TSB, Masuku SKS (2017) Correlates of ART Adherence among Pregnant and Breastfeeding Mothers Initiated on Life Long ART for People Living with HIVIAIDS (LLAPLA) in One Public Health Unit in the Hhohho Region. J AIDS Clin Res 8: 681. doi: 10.4172/21556113.1000681

Page 6 of 8

\section{Factors}

Woman's educational level

Illiterate

Primary

Secondary/high school

Tertiary

Have a problem of forgetfulness

Poor Adherence

Good Adherence

Health Workers do listen to me

Poor adherence

Good adherence

We communicate effectively with health care workers

Poor adherence

Good adherence

I disclosed my HIV status to someone

Poor Adherence

Good adherence

Didn't disclose HIV status because afraid of rejection by in-laws

Poor adherence

Good adherence

Hide medication from partner because of fear of rejection from partner

Poor adherence

Good adherence

I also use alternative medicine

Poor adherence

Good adherence

I'm in stable relationship

Poor adherence

Good adherence

I have a good social support

Poor adherence

Good adherence

I have a good emotional support

Poor adherence

Good adherence

*significance level at $\mathrm{P}<0.05 ;{ }^{* *}$ Significance level at $\mathrm{P}<0.001$

\begin{tabular}{|c|c|c|c|}
\hline $\mathbf{n}$ & $\%$ & $\mathbf{F}$ & $P$ Value \\
\hline 5 & 2 & \multirow{4}{*}{5.23} & \multirow{4}{*}{$0.009^{* *}$} \\
\hline 54 & 22 & & \\
\hline 169 & 69 & & \\
\hline 17 & 7 & & \\
\hline 86 & 35 & \multirow{2}{*}{5.73} & \multirow{2}{*}{$0.021^{*}$} \\
\hline 159 & 65 & & \\
\hline 86 & 35 & \multirow{2}{*}{7.87} & \multirow{2}{*}{$0.008^{* *}$} \\
\hline 159 & 65 & & \\
\hline 86 & 35 & \multirow{2}{*}{7.87} & \multirow{2}{*}{$0.008^{* *}$} \\
\hline 159 & 65 & & \\
\hline 86 & 35 & \multirow{2}{*}{10.03} & \multirow{2}{*}{$0.003^{* *}$} \\
\hline 159 & 65 & & \\
\hline 86 & 35 & \multirow{2}{*}{4.54} & \multirow{2}{*}{$0.039^{*}$} \\
\hline 159 & 65 & & \\
\hline 86 & 35 & \multirow{2}{*}{15.87} & \multirow{2}{*}{$0.000^{* *}$} \\
\hline 159 & 65 & & \\
\hline 86 & 35 & \multirow{2}{*}{14.83} & \multirow{2}{*}{$0.000^{* *}$} \\
\hline 159 & 65 & & \\
\hline 86 & 35 & \multirow{2}{*}{9.16} & \multirow{2}{*}{$0.004^{* *}$} \\
\hline 159 & 65 & & \\
\hline 86 & 35 & \multirow{2}{*}{17.85} & \multirow{2}{*}{$0.000^{* *}$} \\
\hline 159 & 65 & & \\
\hline 86 & 35 & \multirow{2}{*}{20.34} & \multirow{2}{*}{$0.000^{* *}$} \\
\hline 159 & 65 & & \\
\hline
\end{tabular}

Table 7: Factors significantly associated to the participants' adherence to ART $(n=245)$.

a cross-sectional study conducted among 626 ART attendees using a structured questionnaire with a face-to-face interview to investigate ART adherence level among HIV positive patients attending their clinical care in public health facilities in Harare and Dire Dawa, Eastern Ethiopia, different findings were observed. Having a monthly income of 501.00-999.00 Ethiopian Birr (ETB) significantly (AOR=6.73; 95\% CI=2.71-16.75) associated to adherence [20]. Differences in the findings could be due to differences in the population of the study, that is, this study focused only on mothers attending ANC and post natal services.

A majority of the participants understood the English instructions written on their ART medications and knew how to use their ART medications properly. This is because almost all participants were literate, and as such adherence was not affected by illiteracy or lack of knowledge of how to take the medication. Many participants reported a problem of forgetfulness while some reported to have a diagnosed mental problem and feeling down and depressed often times. Such symptoms relate to depression [16]. Depression is common among patients on ART. In a study conducted to assessed ART adherence and examined factors associated with suboptimal adherence in northern Viet Nam, from 615 PLHIV on ART through medical record extraction and patient interviews using audio computer-assisted self-interview, depression was common among ART patients and was significantly associated with adherence $(\mathrm{p}<0.001)$ [21]. Some $(55 \%)$ participants had used ART because PMTCT had helped them give birth to HIV negative children. This attests to the effectiveness of ART in preventing mother to child transmission of HIV.

Patient-provider relationships are valued by patients. Most participants felt that they were listened to by health works, and health workers were sensitive to their needs. Other studies found that patientprovider relationships influence ART adherence [22] and having a good working relationship with the patients made it easy for the health care worker to assess disclosure. On another note, sociocultural factors such as stigma, non-disclosure, social support and emotional support influence ART adherence. In this study, some patients had not disclosed their status to any one, not even to their partners. Some of the reasons were fear of rejection by their partner or their in-laws. As a result some participants had to hide their medications. These factors do not only affect adherence to ART directly, but also have an indirect influence through causing depression [21] and also influence copying with the side effects of ART [23]. 
Citation: Maseko TSB, Masuku SKS (2017) Correlates of ART Adherence among Pregnant and Breastfeeding Mothers Initiated on Life Long ART for People Living with HIVIAIDS (LLAPLA) in One Public Health Unit in the Hhohho Region. J AIDS Clin Res 8: 681. doi: 10.4172/21556113.1000681

Page 7 of 8

\begin{tabular}{|c|c|c|c|c|c|c|c|c|c|c|c|}
\hline & $\begin{array}{c}\text { Educational } \\
\text { level }\end{array}$ & $\begin{array}{c}\text { Adherence to } \\
\text { ART }\end{array}$ & $\begin{array}{l}\text { Have a problem } \\
\text { of forgetfulness }\end{array}$ & $\begin{array}{l}\text { Health } \\
\text { workers } \\
\text { do listen } \\
\text { to me }\end{array}$ & $\begin{array}{c}\text { We } \\
\text { communicate } \\
\text { effectively with } \\
\text { the health care } \\
\text { workers }\end{array}$ & $\begin{array}{c}\text { I } \\
\text { disclosed } \\
\text { my HIV } \\
\text { status to } \\
\text { someone }\end{array}$ & \begin{tabular}{|c|} 
Hide \\
medication \\
from partner \\
because \\
afraid of \\
rejection by \\
in-laws \\
\end{tabular} & $\begin{array}{l}\text { I also use } \\
\text { alternative } \\
\text { medicine }\end{array}$ & $\begin{array}{l}\text { I'm in a stable } \\
\text { relationship }\end{array}$ & $\begin{array}{l}\text { I have } \\
\text { good } \\
\text { social } \\
\text { support }\end{array}$ & $\begin{array}{c}\text { I have } \\
\text { a good } \\
\text { emotional } \\
\text { support }\end{array}$ \\
\hline $\begin{array}{c}\text { Educational } \\
\text { level } r= \\
P=\end{array}$ & 1 & & & & & & & & & & \\
\hline $\begin{array}{c}\text { Adherence to } \\
\text { ART } r= \\
\mathrm{P}=\end{array}$ & $\begin{array}{l}0.258 \\
0.087\end{array}$ & 1 & & & & & & & & & \\
\hline $\begin{array}{c}\text { Have a } \\
\text { problem of } r= \\
\text { forgetfulness } \\
p=\end{array}$ & $\begin{array}{l}-0.347 \\
0.020^{*}\end{array}$ & $\begin{array}{l}-0.474 \\
0.001^{\star *}\end{array}$ & 1 & & & & & & & & \\
\hline $\begin{array}{c}\text { Health } \\
\text { workers do } r= \\
\text { listen to me } \\
p=\end{array}$ & $\begin{array}{l}-0.215 \\
0.157\end{array}$ & $\begin{array}{l}0.134 \\
0.382\end{array}$ & $\begin{array}{l}-0.013 \\
0.933\end{array}$ & 1 & & & & & & & \\
\hline $\begin{array}{c}\text { I disclosed my } \\
\text { HIV status } r= \\
\text { to someone } \\
p=\end{array}$ & $\begin{array}{l}-0.210 \\
0.166\end{array}$ & $\begin{array}{l}-0.271 \\
0.072\end{array}$ & $\begin{array}{l}-0.264 \\
0.080\end{array}$ & $\begin{array}{c}0.535 \\
0.000^{\star *}\end{array}$ & $\begin{array}{l}-0.134 \\
0.382\end{array}$ & 1 & & & & & \\
\hline \begin{tabular}{|c|} 
Hide \\
medication \\
from $r=$ \\
partner \\
because \\
afraid $p=$ \\
of rejection by \\
in-laws
\end{tabular} & $\begin{array}{l}-0.253 \\
0.093\end{array}$ & $\begin{array}{l}0.130 \\
0.394\end{array}$ & $\begin{array}{l}-0.156 \\
0.306\end{array}$ & $\begin{array}{l}0.115 \\
0.453\end{array}$ & $\begin{array}{l}0.115 \\
0.453\end{array}$ & $\begin{array}{c}-0.092 \\
0.548\end{array}$ & 1 & & & & \\
\hline $\begin{array}{c}I \text { also use } \\
\text { alternative } r= \\
\text { medicine } p=\end{array}$ & $\begin{array}{l}0.240 \\
0.112\end{array}$ & $\begin{array}{l}-0.312 \\
0.037^{*}\end{array}$ & $\begin{array}{l}0.064 \\
0.675\end{array}$ & $\begin{array}{l}0.124 \\
0.416\end{array}$ & $\begin{array}{l}-0.342 \\
0.022^{*}\end{array}$ & $\begin{array}{l}0.087 \\
0.569\end{array}$ & $\begin{array}{l}0.121 \\
0.428\end{array}$ & 1 & & & \\
\hline $\begin{array}{c}\text { I'm in a stable } \\
\text { relationship } \\
r= \\
P=\end{array}$ & $\begin{array}{l}0.172 \\
0.253\end{array}$ & $\begin{array}{l}-0.271 \\
0.072\end{array}$ & $\begin{array}{c}-0.144 \\
0.345\end{array}$ & $\begin{array}{l}0.089 \\
0.561\end{array}$ & $\begin{array}{c}0.312 \\
0.037^{*}\end{array}$ & $\begin{array}{c}0.444 \\
0.002^{\star *}\end{array}$ & $\begin{array}{l}-0.245 \\
0.104\end{array}$ & $\begin{array}{l}-0.203 \\
0.180\end{array}$ & 1 & & \\
\hline $\begin{array}{c}\text { I have good } \\
\text { social support } \\
r= \\
P=\end{array}$ & $\begin{array}{l}-0.161 \\
0.290\end{array}$ & $\begin{array}{l}-0.283 \\
0.060\end{array}$ & $\begin{array}{c}-465 \\
0.001^{*}\end{array}$ & $\begin{array}{l}0.230 \\
0.129\end{array}$ & $\begin{array}{l}-0.083 \\
0.586\end{array}$ & $\begin{array}{c}0.625 \\
0.000^{\star *}\end{array}$ & $\begin{array}{l}-0.081 \\
0.595\end{array}$ & $\begin{array}{l}-0.059 \\
0.700\end{array}$ & $\begin{array}{l}0.234 \\
0.121\end{array}$ & 1 & \\
\hline $\begin{array}{l}\text { I have a good } \\
\text { emotional } r= \\
\text { support } p=\end{array}$ & $\begin{array}{l}-0.115 \\
0.453\end{array}$ & $\begin{array}{c}0.375 \\
0.011^{*}\end{array}$ & $\begin{array}{l}-0.384 \\
0.009^{\star *}\end{array}$ & $\begin{array}{r}-0.134 \\
0.382\end{array}$ & $\begin{array}{l}0.312 \\
0.037^{*}\end{array}$ & $\begin{array}{l}0.306 \\
0.041^{*}\end{array}$ & $\begin{array}{l}-0.245 \\
0.145\end{array}$ & $\begin{array}{l}-0.349 \\
0.019^{*}\end{array}$ & $\begin{array}{l}0.444 \\
0.002^{*}\end{array}$ & $\begin{array}{l}0.429 \\
0.003^{\star}\end{array}$ & 1 \\
\hline
\end{tabular}

r: correlation; ${ }^{*}$ Correlation significance level at $\mathrm{P}<0.05 ;{ }^{* *}$ Correlation significance level at $\mathrm{P}<0.000$

Table 8: Correlation analysis of significantly associated factors to ART adherence $(n=245)$.

\section{Factors Associated to Adherence to ART}

Various factors were significantly associated to ART adherence. These include participant's level of education, having good social support, being listened to by the health worker and having nice communication with the health worker, disclosed one's HIV status to someone, fear of rejection by in-laws, hiding medication from partner, and using alternative medicine. The study emphasises the need to enhance good patient-provider relationships in order to improve adherence to ART among pregnant women. In order to achieve this, health workers should be equipped on how to be good listeners, and communicate nicely with ART patients when providing counselling and care to pregnant mothers living with HIV. Similar findings have been observed in other studies [20,21]. In this study having a problem of forgetfulness negatively correlated to adherence and similar findings were observed in other studies [24,25]. These findings show that enabling an environment for disclosure and intake of medication in the form of emotional and social support from family and health providers is necessary to improve adherence to ART. Health workers should assess the disclosure status of each participant and assist patients with stigma and disclosure problems. Assessing forgetfulness among the mothers on ART is important so that in the plan of care, measures such as reminders like alarms, daily medications dividers, and family members to remind the patient her medication on time can be used, hence patients can effectively be helped to adhere to ART.

The study also showed new factors that indirectly influence adherence to ART. If the patient felt she was listened to by the health care worker was more likely to disclose one's status to someone. Communicating nicely with the health care worker and being in a stable relationship improved emotional support of patients with subsequent increase in adherence. On another note, being in a stable relationship, having good social support and having good emotional support improved disclosure of one's HIV status to someone. Having effective communication with health care workers and good emotional support decreased the likelihood of using alternative medicine. Having good social and emotional support decreased the likelihood of forgetfulness and consequently adherence improved. 
Citation: Maseko TSB, Masuku SKS (2017) Correlates of ART Adherence among Pregnant and Breastfeeding Mothers Initiated on Life Long ART for People Living with HIVIAIDS (LLAPLA) in One Public Health Unit in the Hhohho Region. J AIDS Clin Res 8: 681. doi: 10.4172/21556113.1000681

Page 8 of 8

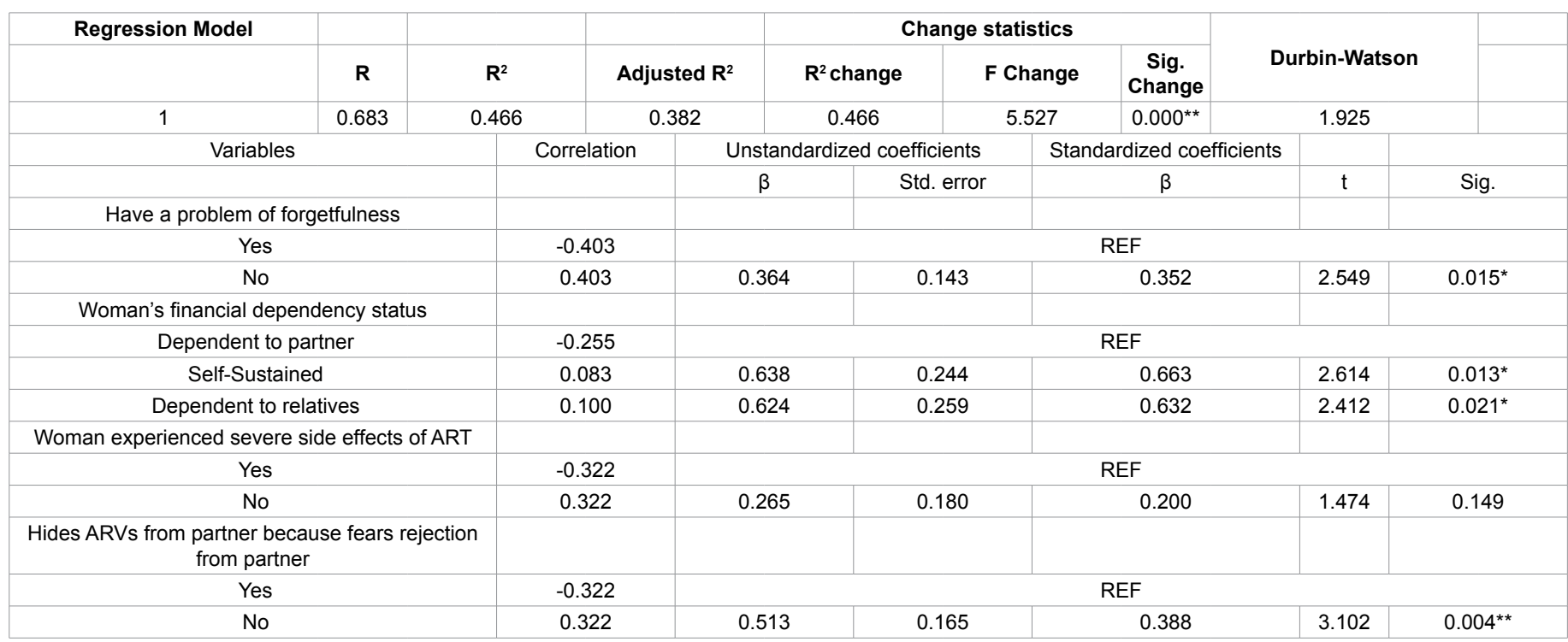

$\beta$ gives a measure of the contribution of each variable to the model; REF: reference point which is a constant; * Significance level at $P<0.05$ ** significance level at $P<0.00$

Table 9: Predictors of good adherence to LLAPLA among mothers living with HIV ( $n=245)$.

\section{Conclusion}

LLAPLA being a relatively new initiative in the era of HIV and PMTCT, the study contributed to the body of knowledge by determining correlates of LLAPLA and predictors of adherence to LLAPLA. Based on the findings, it is important for health workers to assess if mothers on LLAPLA have a problem of forgetfulness, and their financial position. It is still necessary to assist patients initiated on LLAPLA to deal with stigma and disclosure issues and provide them with emotional and social support. There is still a need for more studies at a national level to investigate measures to improving adherence to LLAPLA and to assess the response by male partners to pregnant mothers' sero-positive status and initiation on LLAPLA.

\section{References}

1. UNAIDS (2014) Global AIDS response progress reporting 2014 construction of core indicators for monitoring the 2011 United Nations Political declaration on HIV and AIDS. Joint United Nations Programme on HIVIAIDS (UNAIDS).

2. WHO (2016) Maternal, new-born, child and adolescent. Adolescent Pregnancy.

3. MOT (2009) Swaziland HIV prevention response and modes of transmission analysis. National Emergency Response Council on HIV and AIDS (NERCHA).

4. CSO (2008) Swaziland demographic and health survey 2006-07. Central Statistical Office and Macro International Inc

5. Whiteside A, Andrade C, Arrehag L, Dlamini S, Ginindza T, et al. (2006) The socio-economic impact of HIVIAIDS in Swaziland. National Emergency Response Council on HIV and AIDS (NERCHA), Mbabane, Swaziland.

6. UNGASS (2010) Monitoring the declaration of commitment on HIVIAIDS (UNGASS): Swaziland country report. Ministry of Health, Mbabane, Swaziland.

7. UNAIDS (2012a) Global report: UNAIDS report on the global AIDS epidemic 2012. Joint United Nations Programme on HIVIAIDS (UNAIDS).

8. UNDP (2013) Human development report 2013. The rise of the South: Human progress in a diverse world. United Nations Development Programme.

9. The Kingdom of Swaziland (2010) National HIV and AIDS monitoring and evaluation report. Mbabane.

10. Tiyou A, Belachew T, Alemseged F, Biadgilign S (2010) Predictors of adherence to antiretroviral therapy among people living with HIVIAIDS in resource-limited setting of South west Ethiopia. AIDS Res Ther 7: 39.

11. MOH (2013) HIVIAIDS Guidelines. Mbabane

12. Pratt RJ (2003) A foundation for nursing and health care practice. CRC Press.

13. NSF (2009-2014) National multi-sectoral strategic framework Mbabane Swaziland. National Emergency Response Council on HIV and AIDS.

14. Mbabane PHU ART Register (2014) ART register 2013/2014. Mbabane.

15. Mbabane PHU ART Register (2015) ART register 2014/2015. Mbabane.

16. UNICEF (2008) Young people and family planning: Teenage pregnancy.

17. WHO (2004) Antiretroviral drugs for treating pregnant women and preventing HIV infection in infants: Guidelines on care, treatment and support for women living with HIVIAIDS and their children in resource-constrained settings. World Health Organization.

18. Nuwagaba-Biribonwoha $\mathrm{H}$, Pals $\mathrm{S}$, Kidder $\mathrm{D}$, Carpenter $\mathrm{D}$, Katuta $\mathrm{D}$, et al. (2016) Factors associated with non-adherence to antiretroviral therapy among patients attending HIV care and treatment clinics in Kenya, Namibia and Tanzania. CDC

19. Nation Master (2017) Labor>Salaries and benefits>Minimum wage: Countries compared.

20. Letta S, Demissie A, Oljira L, Dessie Y, (2015) Factors associated with adherence to antiretroviral therapy (ART) among adult people living with HIV and attending their clinical care, Eastern Ethiopia. BMC International Health and Human Rights 15: 33.

21. Do HM, Dunne MP, Kato M, Pham CV, Nguyen KV, (2013). Factors associated with suboptimal adherence to antiretroviral therapy in Viet Nam: A crosssectional study using audio computer-assisted self-interview (ACASI). BMC Infectious Diseases13: 154

22. Chesney MA (2000) Factors affecting adherence to antiretroviral therapy. Clin Infect Dis 30: S171-S176.

23. Li L, Lee SJ, Wen Y, Lin C, Wan D, Jiraphongsa C (2011) Antiretroviral therapy adherence among patients living with HIVIAIDS in Thailand. Nurs Health Sci 12: $212-220$

24. Wang X, Wu Z (2007) Factors associated with adherence to antiretrovira therapy among HIVIAIDS patients in rural China. AIDS 21: S149-S155.

25. Hansana V, Sanchaisuriya P, Durham J, Sychareun V, Chaleunvong K, et al. (2012) Adherence to antiretroviral therapy (ART) among people living with HIV (PLHIV): A cross-sectional survey to measure in Lao PDR. BMC Public Health 13: 617 